\title{
Study of Natural and Accelerated Weathering on Mechanical Properties of Antioxidants Modified Low Density Polyethylene Films for Greenhouse
}

\author{
Othman Al Othman, ${ }^{1,2}$ Shan Faiz, ${ }^{1}$ and Muhammad Abduh Tuasikal ${ }^{1}$ \\ ${ }^{1}$ Chemical Engineering Department, King Saud University, P.O. Box 800, Riyadh 11421, Saudi Arabia \\ ${ }^{2}$ Deanship of Graduate Studies, The Saudi Electronic University, Riyadh, Saudi Arabia \\ Correspondence should be addressed to Shan Faiz; sfaiz@ksu.edu.sa
}

Received 16 March 2014; Revised 15 July 2014; Accepted 29 July 2014; Published 20 August 2014

Academic Editor: Geoffrey R. Mitchell

Copyright (C) 2014 Othman Al Othman et al. This is an open access article distributed under the Creative Commons Attribution License, which permits unrestricted use, distribution, and reproduction in any medium, provided the original work is properly cited.

\begin{abstract}
Natural and accelerated weatherings were studied to inspect the effect of antioxidants to protect low-density polyethylene (LDPE) films for commercial application as greenhouse covering materials in Saudi Arabia. In this investigation, six different formulations of LDPE film with incorporation of antioxidants were prepared and compared with neat LDPE. The samples were extruded and blown into a film using twin-screw extruder and film blowing machine. The LDPE films were exposed for outdoor weathering in Riyadh during the period of 90 days (mid of June to mid of September) while the accelerated tests were performed by WeatherOmeter. The film having $0.2 \mathrm{wt} \%$ Alkanox-240 (AN-0.2) stabilizers showed the highest tensile strength among all samples during natural and 100-hour accelerated weathering (10.9 MPa and $21.8 \mathrm{MPa}$, resp.). The best elongation at break was witnessed in $0.2 \%$ Good-rite antioxidants which were $64 \%$ in natural weathering; however, $0.5 \%$ Good-rite antioxidants showed $232 \%$ in accelerated weathering. The film having $0.5 \mathrm{wt} \%$ Good-rite 3114 (GR-0.5) antioxidant could withstand 70 days during natural exposure before the tensile strength values were reduced to $2 / 3 \mathrm{rd}$ of the initial. The present study suggested that the addition of antioxidants Goodrite, Anox, and Alkanox can improve the mechanical strength, film's life, effectiveness, and stability and they are suitable to be incorporated in LDPE for commercial greenhouse films.
\end{abstract}

\section{Introduction}

Greenhouses are known to provide most suitable conditions for production as the crops are being controlled and looked after under suitably controlled environment, that is, by maintaining basic requirements for agriculture, for example, water, fertilizers, seeds, and plant protection chemicals. It is known that greenhouses are covered with transparent material that transmits visible light $(400-700 \mathrm{~nm})$, which is the major source of energy for photosynthesis [1]. In the last decades, the increased research towards greenhouses has significantly increased the involvement of plastics for use as a cover material [2].

Low-density poly ethylene (LDPE), being of light weight, transparent, economical, and of robust mechanical strength, has dominated the use of plastic films as greenhouse covering materials. However the greenhouse materials are subjected to numerous environmental factors that lead to chemical and/or physical degradation. It is well depicted in literature that degradation of LDPE is enhanced by UV radiation which transfers its energy to polymer molecules causing them to be energized and subject to oxidation [3].

Researchers have aimed to enhance the stability of LDPE films to make it more effective for greenhouse cover and a number of antioxidants and UV stabilizers have been reported in the literature [4-6]. Mashael [7] studied the effect of talc (10\%) with PP and reported enhanced stress at break, elongation at break, and Young's modulus. Xue et al. [8] developed aspen fiber-polypropylene composites and studied mechanical properties at $4^{\circ} \mathrm{C}$ and $40^{\circ} \mathrm{C}$. They reported increase in tensile moduli, flexural moduli, and flexural strength as the wood fiber content increased in the composites. The tensile strength decreased as the fiber content increased. 
TABLE 1: Formulations of LDPE resin with additives percentages and films codes.

\begin{tabular}{lcc}
\hline Type of additives & Code & wt\% \\
\hline Good-rite 3114 antioxidant & GR-0.2 & 0.2 \\
& GR-0.5 & 0.5 \\
& GR-2.0 & 2.0 \\
Anox 20 & AN-0.2 & 0.2 \\
Alkanox 240 & AL-0.2 & 0.2 \\
Anox/Alkanox & AN/AL-0.1/0.1 & $0.1 / 0.1$ \\
\hline
\end{tabular}

The effects of natural and accelerated weathering on polyethylene-based films containing commercially available pink, yellow, and white organic pigments and a UV absorber of the benzophenone type were investigated by Michálková et al. [9] They concluded that all films experienced increase in viscosity and decrease in tensile strength and elongation at break in natural weathering. Ojeda et al. [10] compared HDPE, LLDPE (linear low-density polyethylene), and isotactic polypropylene (PP) containing antioxidant. They left the samples in natural weathering for a year to observe the structural changes and its impact on the thermal and mechanical properties. They found that HDPE/LLDPE blend and PP degraded faster than HDPE and LLDPE individually and concluded that presence of tertiary carbon atoms was the main cause for this result.

In the present study we used Good-rite 3114 antioxidant, Anox 20, and Alkanox 240 at various concentrations and blends to investigate their behavior on the mechanical properties of LDPE films under natural and accelerated weathering.

\section{Materials}

Low-density polyethylene (LDPE HP0322N) film blowing grade was supplied by SABIC, Saudi Arabia, with density $0.922 \mathrm{~g} / \mathrm{cm}^{3}$ and melt flow index $0.31 \mathrm{~g} / 10 \mathrm{~min}$. It contains no slip and antiblock additives. HP0322N offers outstanding toughness and good optical properties and is suitable to be processed via extrusion and conventional blown film technique.

In this investigation, LDPE films with six different antioxidants were prepared using film blowing and their behavior was compared with neat LDPE. The formulations are given in Table 1.

2.1. Preparation of LDPE Films. The LDPE pellets were extruded using twin-screw extruder and then blown into a film using film blowing machine. LDPE pellets with additive blends were first melt-mixed in a twin-screw corotating extruder (Farrel Limited FTX 20, US). The conditions were as follows. Barrel zone temperatures were $180^{\circ} \mathrm{C}, 190^{\circ} \mathrm{C}, 200^{\circ} \mathrm{C}$, $210^{\circ} \mathrm{C}, 220^{\circ} \mathrm{C}$, and $230^{\circ} \mathrm{C}$, extruder speed was set at $14 \mathrm{rpm}$, and melt pressure was 22 bar.

The materials were fed into the extruder from hopper which runs into the barrel containing the rotating screw. This screw mixes, compresses, and moves the polymer as it changes from solid granules to a viscous melt. The screw
TABLE 2: The conditions of Weather-Ometer chamber.

\begin{tabular}{lc}
\hline Condition & Value \\
\hline Black panel temperature & $75^{\circ} \mathrm{C}$ \\
Chamber temperature & $58^{\circ} \mathrm{C}$ \\
Relative humidity & $5 \%$ \\
Irradiance @ 340 nm & $0.6 \mathrm{~W} / \mathrm{m}^{2}$ \\
\hline
\end{tabular}

diameter is $26 \mathrm{~mm}$ with $\mathrm{L} / \mathrm{D}$ ratio of 35 . The extrudate was cooled in a water bath at about $20^{\circ} \mathrm{C}$, pelletized, and was left air-dried over 24 hours. In the next step, the material was fed in the film blowing machine.

The film blowing extrusion process began with plastics in pellet form being dropped into the extruder from the hopper. The extruder conveys the plastics forward using a rotating screw. The screw melts the plastic pellets by both friction heating and outside heaters around the barrel. Once the material is molten, it is fed upwards through a circular die to form a hollow plastic tube filled with a desired amount of air.

The plastic tube was continuously brought upward from the tensile force (pull) of nip rollers above the die. The nip rollers are two wheels like steam rollers, which are several feet above the die. The nip rollers are pressured together to form a pinch-off on the bubble, keeping a constant air volume below and flattening the plastic out. In film blowing machine barrel temperatures were $200^{\circ} \mathrm{C}, 180^{\circ} \mathrm{C}$, and $150^{\circ} \mathrm{C}$, winder speed was $270 \mathrm{rpm}$, and extruder speed was set at $450 \mathrm{rpm}$.

\subsection{Weathering of LDPE Films}

2.2.1. Natural Weathering Test. The LDPE films were exposed to outdoor weathering on the roof of the college of engineering, King Saud University, Riyadh, Saudi Arabia, $\left(46^{\circ} 47^{\prime}\right.$ E, longitude, and $24^{\circ} 39^{\prime} \mathrm{N}$, latitude). The LDPE films were exposed to natural weathering. The sample sizes were $6 \mathrm{~cm} \times$ $11 \mathrm{~cm}$ and were assembled on a steel cage at a $35^{\circ}$ angle facing the south (Figure 1).

This natural weathering was carried out during the period of summer season for 90 days from mid of June to mid of September 2012. The temperature during the day and night ranged between 30 and $45^{\circ} \mathrm{C}$ and between 25 and $31^{\circ} \mathrm{C}$, respectively. The wind speed was around 20 to $30 \mathrm{~km} /$ hour and humidity was around 10 to $15 \%$ [11].

2.2.2. Accelerated Weathering Test. With outdoor weathering test, accelerated weathering test for 0,75 , and 100 hours was carried out using accelerated weathering apparatus (Atlas Ci5000 Xenon Weather-Ometer, USA). LDPE films with good mechanical behavior (size $7 \mathrm{~cm} \times 15 \mathrm{~cm}$ ) were clamped in aluminum rack. The conditions in the chamber are tabulated in Table 2.

\section{Characterizations}

3.1. Mechanical Properties. The tensile properties were measured through the conventional uniaxial tension test on a Hounsfield H100 KS series tensile testing machine. The 

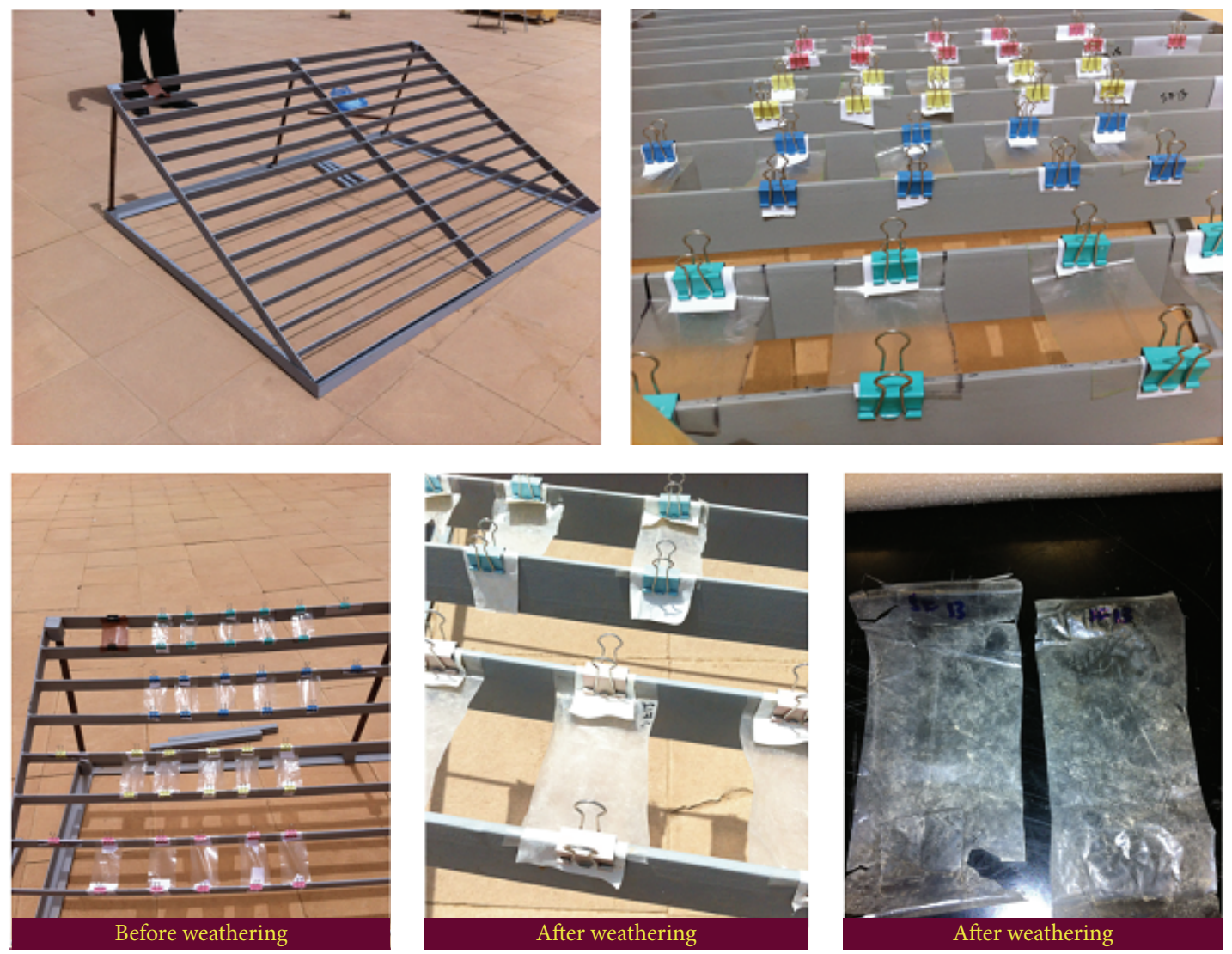

FIGURE 1: Natural (outdoor) weathering of LDPE films.

dumbbell-shaped specimens, ASTM D638, of all materials were tested at room temperature at crosshead speed of $50 \mathrm{~mm} / \mathrm{min}$. The samples were held between two clamps. The upper clamp was connected to a cross-head which moves upwards at a preprogrammed rate to apply tension to the sample. The values were taken from the mean of 3 runs for all cases.

\section{Results and Discussion}

4.1. Preweathering Characterization of LDPE Films. Neat LDPE $(40 \mu \mathrm{m})$ showed the highest elongation at break at $246 \%$ as shown in Figure 2(a). The elongations at break of other two films AN-0.2 and AL-0.2 (with same thickness of $40 \mu \mathrm{m}$ ) containing different additives are lower than neat LDPE. For additive filled LDPE, elongation at break was about $215 \%$ for the blends AN/AL-0.1/0.1 (film thickness $70 \mu \mathrm{m})$. The comparison between neat LDPE and antioxidants incorporated films is represented in Figure 2(b). Neat LDPE film supersedes the rest with a value of $38 \mathrm{MPa}$. Among the rest AN-0.2 showed tensile strength of $33 \mathrm{MPa}$ and GR0.2 of $30 \mathrm{MPa}$ which suggests that they are good covering materials. The elastic moduli for various antioxidants are shown in Figure 2(c). AN-0.2 showed the best modulus $(426 \mathrm{MPa})$ followed by GR-0.2 with a value of $301 \mathrm{MPa}$. All other samples had considerably high values with the exception of GR-0.5.
TABLE 3: Tensile strength of LDPE films under natural and accelerated weathering.

\begin{tabular}{lccccc}
\hline \multirow{2}{*}{ Sample } & \multicolumn{5}{c}{ Tensile strength (MPa) } \\
& Accelerated weathering & Natural weathering \\
& $0 \mathrm{~h}$ & $75 \mathrm{~h}$ & $100 \mathrm{~h}$ & 0 day & 90 days \\
\hline Neat LDPE & 38.3 & 19.6 & 15.3 & 38.3 & 10.3 \\
GR-0.2 & 29.7 & 23.1 & 20.9 & 29.7 & 6.3 \\
GR-0.5 & 16.2 & 12.7 & 9.8 & 16.2 & 8.7 \\
GR-2.0 & 27.1 & 8.4 & 5.3 & 27.1 & 7.6 \\
AN-0.2 & 33.7 & 25.3 & 21.8 & 33.7 & 10.9 \\
AL-0.2 & 26.3 & 20.5 & 13.0 & 26.3 & 2.7 \\
\hline
\end{tabular}

4.2. Postweathering Characterization of LDPE Films. Table 3 tabulated the tensile strength change during accelerated and natural weathering, respectively. The increase in weathering time in both cases showed reduction in the tensile strength. The least decrease in tensile strength was obtained in AN-0.2 in 90 days natural weathering whose strength was reduced from 33.7 to $10.9 \mathrm{MPa}$. Similar sample showed the best result for the $100 \mathrm{~h}$ accelerated weathering.

The elongation at break of postweathered samples is mentioned in Table 4. GR- 0.2 showed the maximum elongation and its value was raised to $232 \%$ from the original $89.8 \%$. 


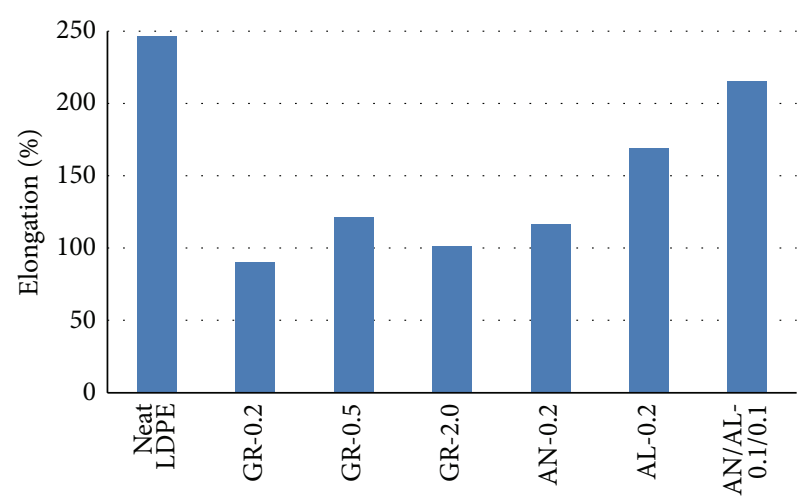

(a)

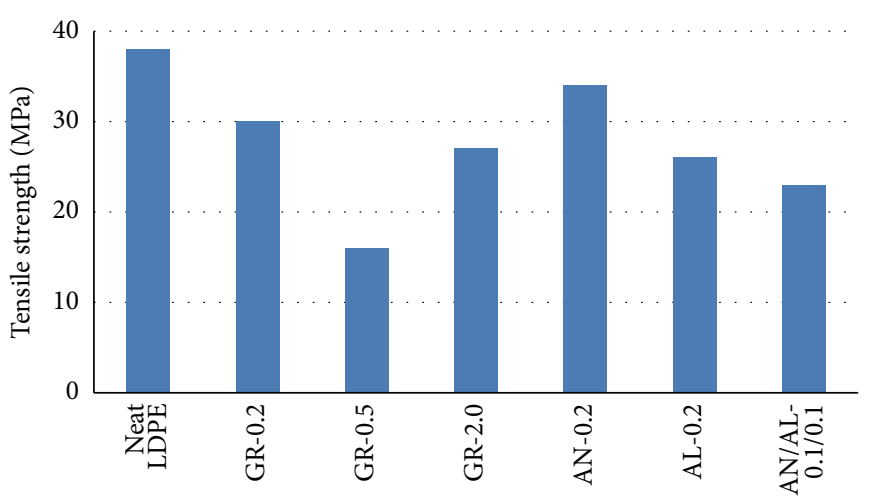

(b)

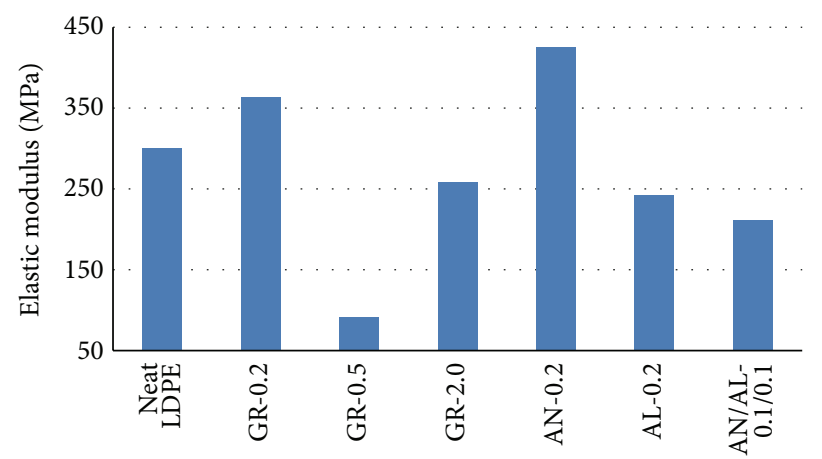

(c)

FIgURE 2: Elongation at break (a), tensile strength (b), and elastic modulus (c) for LDPE films.

Except for GR-0.2, no other formulation showed considerable rise in this regard.

Table 5 illustrates elastic modulus of plastic films under natural and accelerated weathering. This table exhibits fine results with reduction in elastic modulus. GR-0.5 showed the best trend and even after weathering, it shows a rise in the elastic modulus, thus providing better stability to the matrix under harsh conditions. The elastic modulus was increased from 91.8 $\mathrm{MPa}$ to $96.3 \mathrm{MPa}$ (natural weathering) and to $138.9 \mathrm{Mpa}$ (accelerated weathering). This intensified the fact that incorporation of $0.5 \%$ Good-rite antioxidant provides better stability than other formulations. This result is supported with $t_{2 / 3}$ discussed in the next section.

It can be seen from Figure 3 that the weathering period for the reduction to $2 / 3$ rd of the initial value of tensile strength, $t_{2 / 3}$, of tested films under accelerated condition is approximately 2 days, whereas for natural weathering it took around 17 days. This result means that the accelerated test method is about 9 times faster than natural exposure in Riyadh (June-September).

LDPE films with $0.2 \%$ Anox antioxidant take about 20 days to reach $2 / 3$ rd of the initial value of tensile strength under natural weathering, while this film without antioxidant requires about 17 days. For LDPE film containing 0.5\% Goodrite antioxidant, $t_{2 / 3}$ of the weathered film exposed to natural weather is approximately 70 days. So, the usage life of AN-0.2 and GR-0.5 films is approximately 1.2 and 4.1 times greater than the life of neat LDPE film, respectively.
TABLE 4: Elongation at break of LDPE films under natural and accelerated weathering.

\begin{tabular}{lccccc}
\hline \multirow{5}{*}{ Sample } & \multicolumn{5}{c}{ Elongation at break (\%) } \\
& Accelerated weathering & Natural weathering \\
& $0 \mathrm{~h}$ & $75 \mathrm{~h}$ & $100 \mathrm{~h}$ & 0 day & 90 days \\
\hline Neat LDPE & 246.0 & 181.2 & 91.6 & 305.7 & 6.3 \\
GR-0.2 & 89.8 & 171.6 & 232.0 & 363.9 & 17.8 \\
GR-0.5 & 120.6 & 124.9 & 138.0 & 91.8 & 64.0 \\
GR-2.0 & 101.4 & 60.8 & 36.9 & 258.0 & 38.8 \\
AN-0.2 & 116.4 & 171.2 & 97.2 & 425.6 & 16.3 \\
AL-0.2 & 169.4 & 119.8 & 83.4 & 241.9 & 16.0 \\
AN/AL- & 215.0 & 362.4 & 418.0 & 211.3 & 12.9 \\
$0.1 / 0.1$ & & & &
\end{tabular}

Good-rite antioxidants were used at different concentrations. At $2.0 \mathrm{wt} \%$, its $t_{2 / 3}$ under natural weathering is 18 days, while this film without antioxidant takes about 17 days. It means that $2.0 \mathrm{wt} \%$ of Good-rite antioxidant is about 1.1 times faster than films without antioxidant. The results also show that GR-0.5 is more effective in durability than $0.2 \mathrm{wt} \%$ and $2.0 \mathrm{wt} \%$. This weight, that is, $0.5 \%$, enhances stability (4.1 times faster), whereas the other two weights do not. The threshold of Good-rite antioxidant that provides good effectiveness is probably $0.5 \mathrm{wt} \%$. 
TABLE 5: Elastic modulus of LDPE films under natural and accelerated weathering.

\begin{tabular}{lccccc}
\hline \multirow{5}{*}{ Sample } & \multicolumn{5}{c}{ Elastic modulus (MPa) } \\
& Accelerated weathering & \multicolumn{2}{c}{ Natural weathering } \\
& $0 \mathrm{~h}$ & $75 \mathrm{~h}$ & $100 \mathrm{~h}$ & 0 day & 90 days \\
\hline Neat LDPE & 305.7 & 286.0 & 279.8 & 305.7 & 67.9 \\
GR-0.2 & 363.9 & 257.5 & 231.7 & 363.9 & 132.3 \\
GR-0.5 & 91.8 & 119.8 & 138.9 & 91.8 & 96.3 \\
GR-2.0 & 258.0 & 101.1 & 63.2 & 258.0 & 56.4 \\
AN-0.2 & 425.6 & 215.8 & 204.4 & 425.6 & 63.1 \\
AL-0.2 & 241.9 & 255.7 & 279.3 & 241.9 & 371.4 \\
AN/AL- & 211.3 & 208.6 & 204.5 & 211.3 & 95.23 \\
$0.1 / 0.1$ & & & &
\end{tabular}

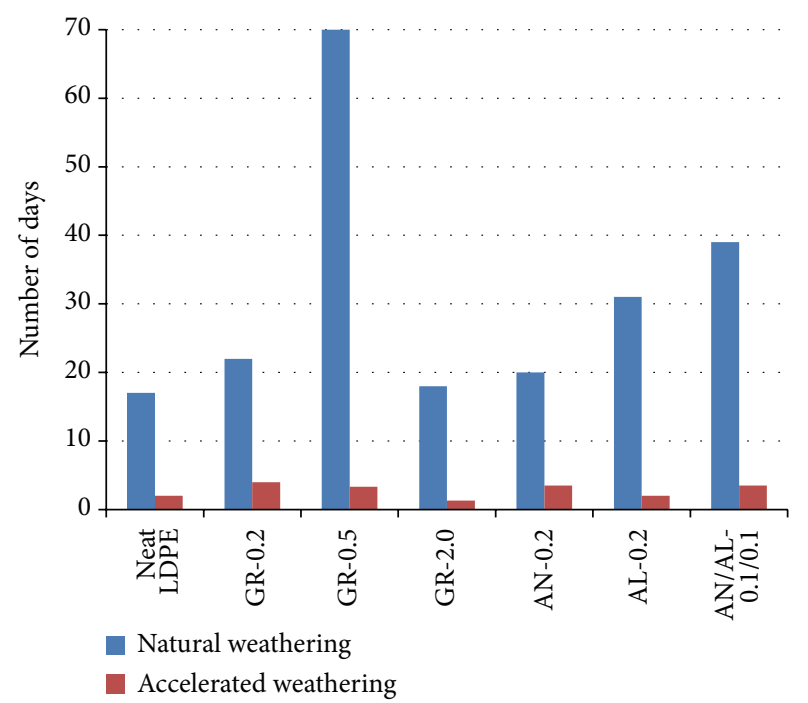

FIGURE 3: Comparison of $t_{2 / 3}$ by natural and accelerated weathering for LDPE films.

\section{Conclusion}

The weathering behavior of films of low-density polyethylene blends, containing three different antioxidants and their blends, was analyzed by subjecting the films to both natural and artificial weathering exposure. The film with Anox (0.2\%) showed the maximum tensile strength and elastic modulus among all formulations in preweathering conditions. In postweathering results, AN-0.2 showed better stability than all other films for both natural and outdoor exposure. The reduction of tensile strength to $2 / 3 \mathrm{rd}$ of the initial value was best obtained for GR- 0.5 which was 70 days for natural exposure. The elastic modulus after natural and accelerated weathering showed that GR- 0.5 provided great stability to the polymer matrix. The results showed that incorporation of Goodrite antioxidant with $0.5 \%$ content and Anox with $0.2 \%$ enhanced the mechanical properties of LDPE and they are best suited to be used as greenhouse covering.

\section{Conflict of Interests}

The authors declare that there is no conflict of interests regarding the publication of this paper.

\section{Acknowledgments}

The authors acknowledge the College of Engineering Research Center and Deanship of Scientific Research at King Saud University in Riyadh for the financial support to carry out the research work reported in this paper.

\section{References}

[1] D. Briassoulis, D. Waaijenberg, J. Gratraud, and B. von Eslner, "Mechanical properties of covering materials for greenhouses: part 1, general overview," Journal of Agricultural Engineering Research, vol. 67, no. 2, pp. 81-96, 1997.

[2] N. T. Dintcheva, F. P. La Mantia, D. Acierno et al., "Characterization and reprocessing of greenhouse films," Polymer Degradation and Stability, vol. 72, no. 1, pp. 141-146, 2001.

[3] D. Briassoulis and E. Schettini, "Analysis and design of lowdensity polyethylene greenhouse films," Biosystems Engineering, vol. 84, no. 3, pp. 303-314, 2003.

[4] P. A. Dilara and D. Briassoulis, "Degradation and stabilization of low-density polyethylene films used as greenhouse covering materials," Journal of Agricultural Engineering Research, vol. 76, no. 4, pp. 309-321, 2000.

[5] S. Bualek, K. Suchiva, S. Boonariya, and B. Ratana-Arakul, "Aging of low density polyethylene films for agricultural use in Thailand," Journal of the Science Society of Thailand, vol. 17, pp. 103-122, 1991.

[6] A. A. Basfar, K. M. Idriss Ali, and S. M. Mofti, "UV stability and radiation-crosslinking of linear low density polyethylene and low density polyethylene for greenhouse applications," Polymer Degradation and Stability, vol. 82, no. 2, pp. 229-234, 2003.

[7] AS. Mashael, "Study of the effect of weathering in natural environment on polypropylene and its composites: morphological and mechanical properties," International Journal of Chemistry, vol. 3, pp. 129-141, 2011.

[8] Y. Xue, D. R. Veazie, C. Glinsey, M. F. Horstemeyer, and R. M. Rowell, "Environmental effects on the mechanical and thermomechanical properties of aspen fiber-polypropylene composites," Composites Part B: Engineering, vol. 38, no. 2, pp. 152-158, 2007.

[9] D. Michálková, J. Pospíšil, I. Fortelný et al., "Restabilization of the aging resistance of compatibilized blends of preaged low density polyethylene and high-impact polystyrene (LDPE/HIPS)," Polymer Degradation and Stability, vol. 94, no. 9, pp. 1486-1493, 2009.

[10] T. Ojeda, A. Freitas, K. Birck et al., "Degradability of linear polyolefins under natural weathering," Polymer Degradation and Stability, vol. 96, no. 4, pp. 703-707, 2011.

[11] http://www.pme.gov.sa/en/cc.asp. 

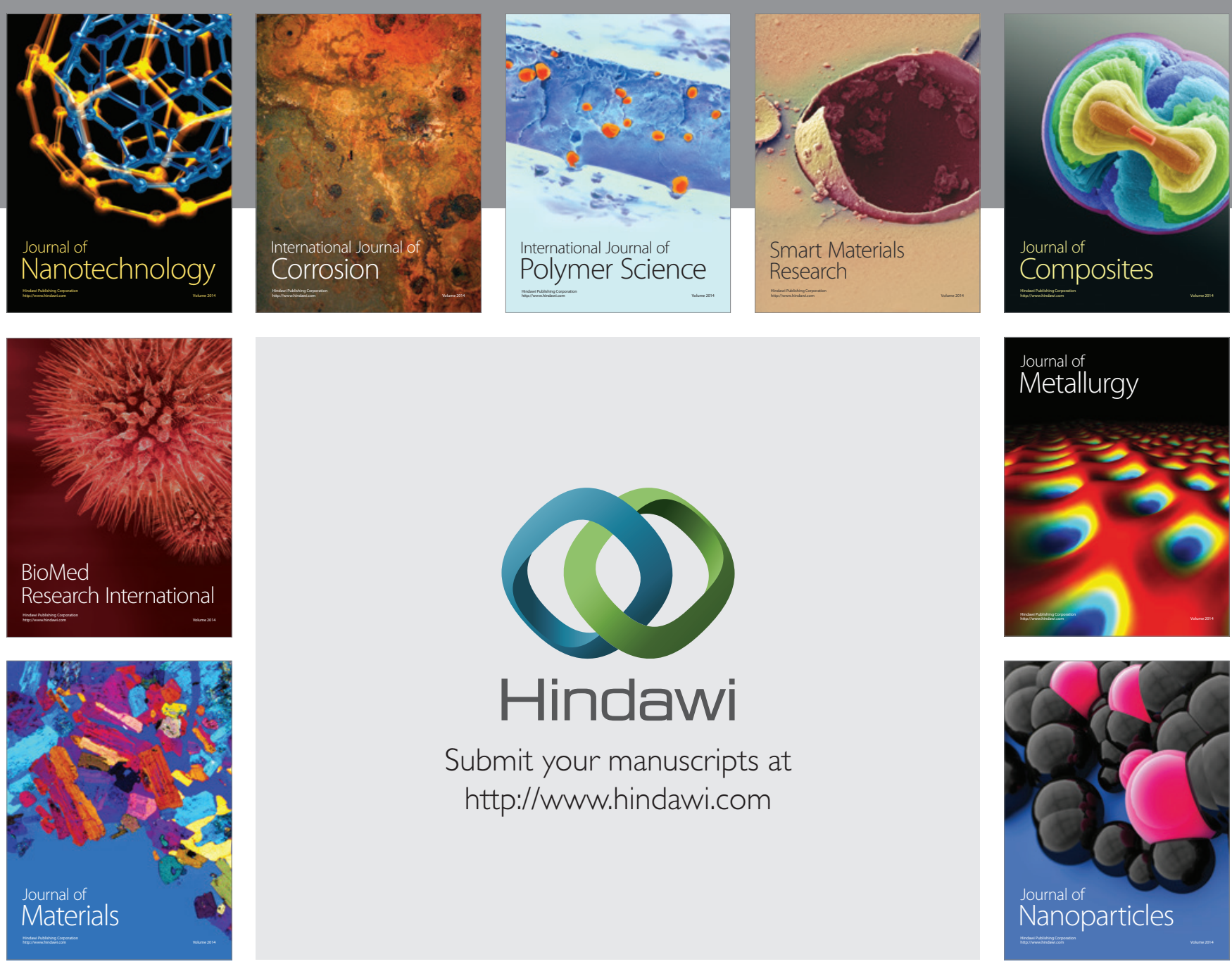

Submit your manuscripts at http://www.hindawi.com
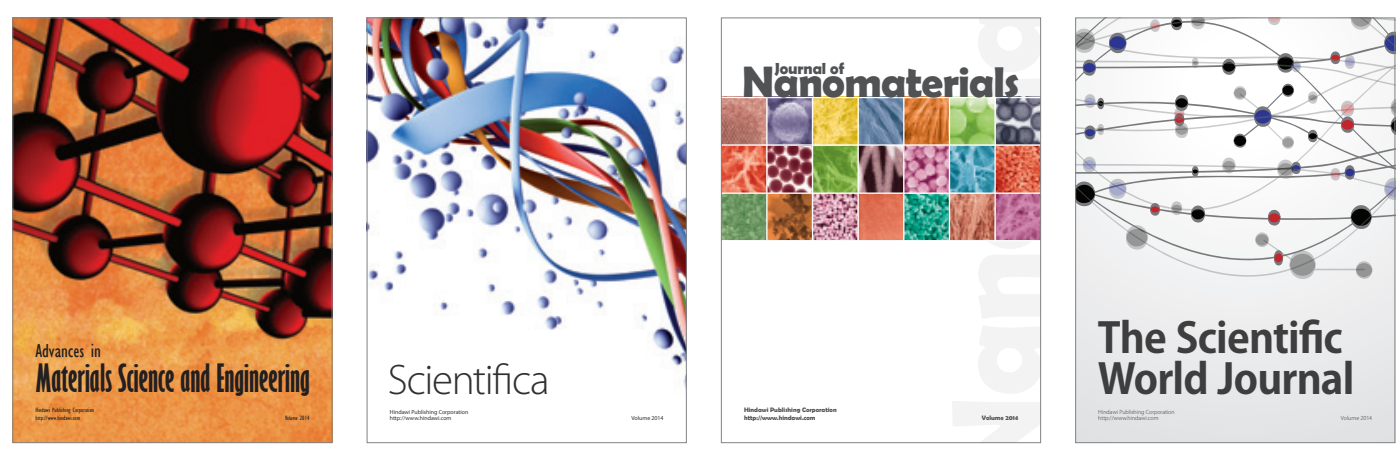

\section{The Scientific World Journal}
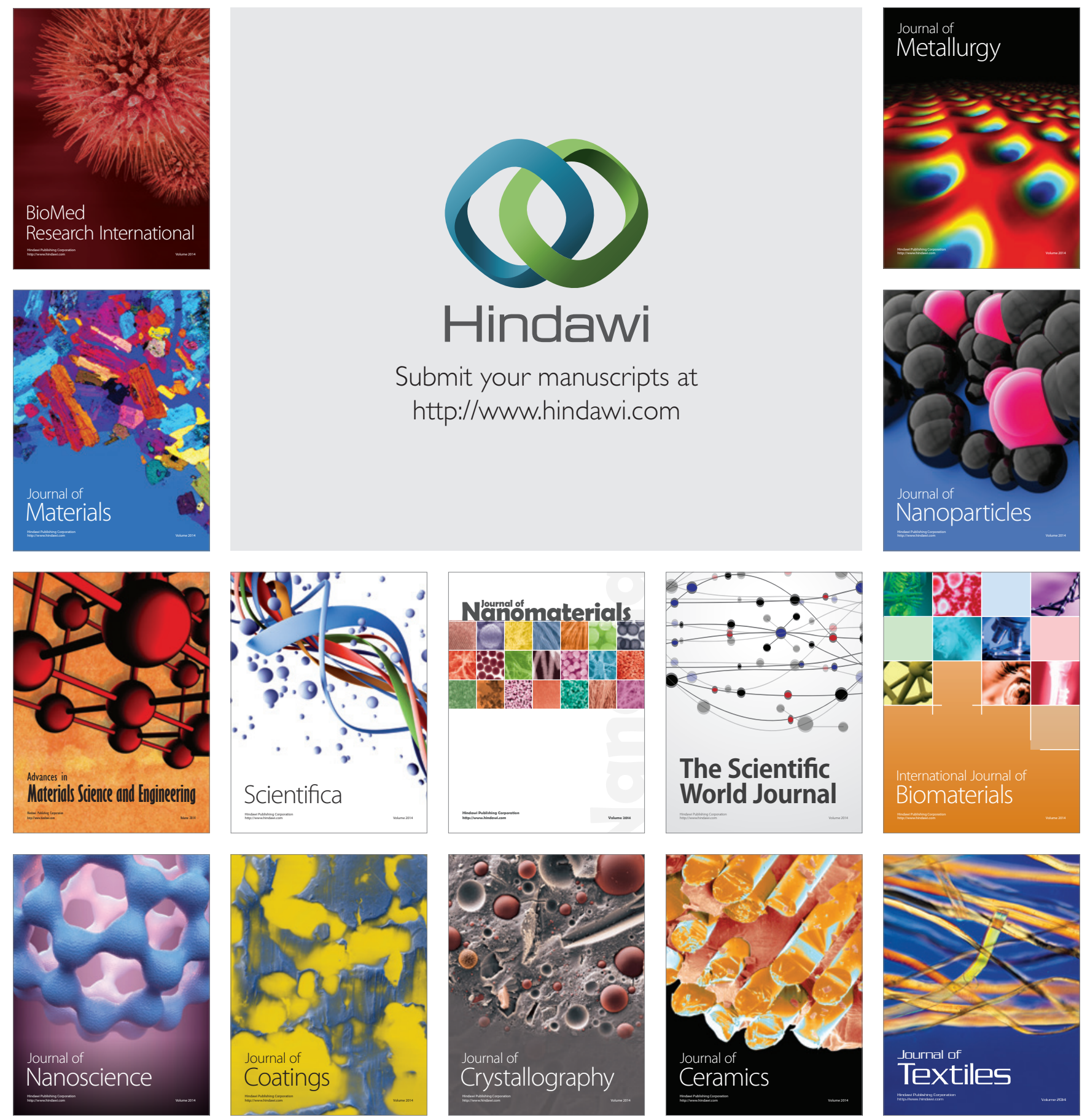